\title{
O EMERGENTISMO COMO ALTERNATIVA TEÓRICA PARA O PROBLEMA MENTE-CORPO
}

\author{
[EMERGENCE: A THEORETICAL ALTERNATIVE TO THE MIND-BODY PROBLEM]
}

\author{
Fabiense Pereira Romão * \\ Leonardo Ferreira Almada ** \\ Universidade Federal de Uberlândia, Brasil
}

\begin{abstract}
Resumo: Por meio do presente artigo, propomos defender a tese de que o emergentismo é uma alternativa teórica plausível e profícua tanto para o equacionamento das relações mente-corpo quanto para as investigações concernentes ao 'espaço' ocupado pela consciência no mundo natural. A partir daí, queremos advogar a tese de que os postulados emergentistas nos descortinam uma alternativa teórica importante diante das limitações que inerem às abordagens reducionistas em seus modos de equacionar a natureza, a origem e a dinâmica da vida mental. Referimo-nos especialmente às concepções de que (i) a realidade é estratificada em diversos níveis e/ou camadas de complexidade, cada qual exigindo uma ciência própria, e de que (ii) a consciência é uma propriedade emergente que não se explica aditivamente, isto é, pela soma das partes. Nossa hipótese mais básica é a de que a perspectiva emergentista é irreversivelmente naturalista e, ainda assim, não se compromete com a pauta redutivista, a qual está fundamentalmente ancorada em um paradigma cerebralista. Dado que uma abordagem emergentista da consciência se baseia na crença de que complexas relações entre as propriedades do sistema ('todo') e de seus componentes ('partes') não apenas existem, mas são relevantes na constituição de sistemas, o emergentismo, acreditamos, estrutura uma robusta metafísica de processos, imprescindível, enquanto tal, para dar conta do fenômeno da consciência e de suas relações
\end{abstract}

ABSTRACT: Through this paper, we propose to defend the thesis that emergentism is a plausible and fruitful theoretical alternative both to address mind-body relationships and for investigations concerning the 'space' occupied by consciousness in the natural world. From there, we want to advocate the thesis that the emergentist postulates reveal an important theoretical alternative before the limitations of the reductionist approaches in their ways of equating the nature, origin and dynamics of mental life. We are referring especially to the conceptions that (i) the reality is stratified at different levels and/or layers of complexity, each requiring its own science, and that (ii) the consciousness is an emerging property that cannot be explained additively, this is, by the sum of the parts. Our most basic hypothesis is that the emergentist perspective is irreversibly naturalistic and, even so, does not commit itself to the reductivist agenda, which is fundamentally anchored in a cerebralist paradigm. Given that an emergentist approach to consciousness is based on the belief that complex relationships between the properties of the system ('whole') and its components ('parts') not only exist, but are relevant in the constitution of systems, the emergentism, we believe, structures a robust process metaphysics, which is essential, as such, to account for the phenomenon of consciousness and its relations with the substrate neural activities of the mind. We also believe that the emergentist perspective of consciousness is

* Programa de Pós Graduação em Filosofia da Universidade Federal de Uberlândia (POSFILUFU). Email: phabienseromao@gmail.com. Universidade.** Professor Adjunto IV do Instituto de Filosofia e do Programa de Pós Graduação em Filosofia da Universidade Federal de Uberlândia, Uberlândia, MG, Brasil.E-mail: umamenteconsciente@gmail.com 
com as atividades neurais substrativas da mente. Acreditamos, também que a perspectiva emergentista de consciência é compatível com a tese de que a mente consiste de uma novidade ontológica de nível superior do sistema a qual resulta das relações de interação e integração entre cérebro, corpo e ambiente. Através do diálogo promovido entre a teoria emergentista e as posições basilares das teorias da mente corporificada, ambicionamos apresentar uma alternativa para o problema das relações entre a mente e o corpo capaz de superar a perspectiva defendida pelo paradigma cerebralista sem recair no dualismo, risco no qual uma teoria das propriedades incorre. Para atender a esse propósito, nosso artigo envolve, primeiramente, a apresentação dos rudimentos históricos do emergentismo, desde o equacionamento do problema todo-parte em sistemas complexos até o soerguimento do chamado 'emergentismo fraco', tal qual formulado por Stephan (1998, 1999). Em seguida, buscaremos demostrar em que sentido o emergentismo se opõe ao reducionismo, e, a partir daí, a relação entre as noções de composição e decomposição nas teorias emergentistas. Procuraremos também relacionar emergentismo e o naturalismo biológico de Searle (1992), e, por fim, trataremos da determinação descendente, isto é, da influência das propriedades sistêmicas sobre suas partes constituintes.

Palavras-chave: Emergência e mente corporificada; Irredutibilidade; Relações todopartes; Relações corpo, cérebro e ambiente compatible with the thesis that the mind consists of a higher-level ontological novelty of the system, which results from the interaction and integration relations between brain, body, and environment. Through the dialogue promoted between the emergentist theory and the basic positions of the theories of the embodied mind, we aim to present an alternative to the problem of the relations between the mind and the body able to overcome the perspective defended by the cerebralist paradigm without falling into dualism. To accomplish these purposes, our paper involves, first, the presentation of the historical rudiments of emergentism, from the equation of the all-part problem in complex systems to the uplift of the so-called 'weak emergentism', as formulated by Stephan (1998, 1999). Then, we will try to demonstrate in what sense emergentism is opposed to reductionism, and, from there, the relationship between the notions of composition and decomposition in emergentist theories. We will also try to relate emergentism and Searle's biological naturalism (1992), and, finally, we will deal with the descending determination, that is, the influence of systemic properties on its constituent parts.

KEYWORDS: Emergence and embodied mind; Irreducibility; Whole-parts relationships; Body, brain, and environment relationships

\section{INTRODUÇÃO}

A longo do artigo que aqui se inicia, propomos defender a tese de que o Aemergentismo é uma alternativa teórica plausível e profícua tanto para o equacionamento das relações mente-corpo quanto para as investigações concernentes ao 'espaço' ocupado pela consciência no mundo natural. Nosso texto é, portanto, movido pela convicção de que o emergentismo se configura como um robusto solo teórico, estrutural, metodológico e conceitual para a investigação acerca da natureza e da origem da mente e, ademais, para as discussões teóricas sobre o estatuto ontológico da consciência frente aos outros objetos do mundo.

Ao longo do nosso texto, propomos sustentar que os postulados emergentistas nos descortinam uma alternativa teórica importante diante das limitações constitutivas das abordagens reducionistas, sobretudo no que concerne à maneira por meio da qual os redutivistas/reducionistas equacionam a natureza, a origem e a dinâmica da vida mental. Nesse caso, referimo-nos especialmente às concepções de que (i) a realidade é 
estratificada em diversos níveis e/ou camadas de complexidade, cada qual exigindo uma ciência própria, e de que (ii) a consciência é uma propriedade emergente que não se explica aditivamente, isto é, pela soma das partes.

Nossa hipótese mais básica é a de que a perspectiva emergentista é irreversivelmente naturalista e que, ainda assim, não compartilha uma agenda teórica com os redutivistas, já que estes estão fundamentalmente ancorados em um paradigma cerebralista que os insere em um outro pano de fundo teórico, estrutural, conceitual e metodológico. Como é de se esperar de alguém que proponha sustentar uma posição emergentista, o desenvolvimento de nossas hipóteses se estabelecerá no interior de um pano de fundo o qual, conquanto naturalista e interdisciplinar, sustenta uma perspectiva não-redutivista. Dito de outro modo: uma abordagem emergentista da consciência se baseia na crença de que complexas relações entre as propriedades do sistema ('todo') e de seus componentes ('partes') não apenas existem, mas são relevantes na constituição de sistemas; portanto, acreditamos, o emergentismo acaba por estruturar uma metafísica de processos robusta e imprescindível para dar conta do fenômeno da vida, da consciência e de suas relações com as atividades neurais substrativas da mente.

Uma variável relevante de nossa aspiração teórica diz respeito ao fato de que a posição emergentista a que recorremos para equacionar o problema das relações mentecorpo não se sustenta em separado da nossa defesa de mente corporificada. Essa compreensão - que, esperamos, se esclarecerá ao longo do texto - decorre da seguinte hipótese: a perspectiva emergentista de consciência é compatível com a tese de que a mente consiste de uma novidade ontológica de nível superior do sistema. Essa novidade - não apenas professamos, mas destacamos - resulta das relações de interação e integração entre cérebro, corpo e ambiente. Em outras palavras, a posição emergentista que propomos está associada às posições basilares sustentadas, em geral, pelas abordagens corporificadas da mente. Queremos com isso dizer que ambicionamos sustentar a tese de que a emergência da mente (consciente) é uma posição filosófica simpática e adequada à tese de que o corpo deve ser concebido como alicerce da mente consciente, e de que, em outras palavras, a mente consciente é essencialmente corporificada. Proporemos, mais especificamente, sustentar nossa abordagem emergentista a partir de uma abordagem corporificada da mente que inclua as noções de mente situada e estendida. Com efeito, acreditamos que, por trás da defesa da noção de mente corporificada, situada e estendida, conseguiremos alinhavar, em bases mais seguras, a tese de que a mente emerge como propriedade de nível superior da vida mental a partir de inextricáveis relações de integração e interação fisiológica, estrutural e funcional entre o corpo-propriamente-dito, o cérebro e o ambiente (DAMASIO, 2011, 2012, 2015, 2018).

Destarte, aspiramos a revelar, por meio desta associação entre o emergentismo e as abordagens corporificadas, um encaminhamento mais adequado não só (i) para o problema das relações entre a mente e o corpo, mas também (ii) para o problema da estruturação da mente consciente, visando, em ambos os casos, a não recair em um dualismo e em um materialismo redutivo que, acreditamos, é incapaz de superar, em filosofia da mente, o paradigma cerebralista. Através do diálogo promovido entre a teoria emergentista e as posições basilares das teorias da mente corporificada, ambicionamos apresentar uma alternativa para o problema das relações entre a mente e o corpo capaz de superar a perspectiva defendida pelo paradigma cerebralista sem recair no dualismo, risco no qual uma teoria das propriedades incorre.

Visando a levar nossos propósitos à sua plena consecução, estruturamos nosso artigo da forma que segue: primeiramente, a apresentação dos rudimentos históricos do emergentismo, desde o equacionamento do problema todo-parte em sistemas 
complexos até o soerguimento do chamado 'emergentismo fraco', tal qual formulado por Stephan $(1998,1999)$. Em seguida, buscaremos demostrar em que sentido o emergentismo se opõe ao reducionismo, e, a partir daí, a relação entre as noções de composição e decomposição nas teorias emergentistas. Procuraremos também relacionar emergentismo e o naturalismo biológico de Searle (1992), e, por fim, trataremos da determinação descendente, isto é, da influência das propriedades sistêmicas sobre suas partes constituintes.

\section{O PROBLEMA TODO-PARTES EM SISTEMAS COMPLEXOS}

A abordagem emergentista remonta à investigação acerca das relações entre o todo e as partes em sistemas complexos. Dentre as abordagens emergentistas iniciais, interessam-nos as que se detiveram sobre sistemas biológicos, pela capacidade que têm de lançar luz no desafio central de nossa empreitada, a saber: pensar o emergentismo à luz de uma perspectiva corporificada, a começar pela defesa de que a mente consiste de uma propriedade sistêmica que emerge das partes que integram o sistema e que mantêm entre si relações permanentes de interação e integração, quais sejam: corpo, cérebro e ambiente.

Destacamos o modelo germinal do conceito de emergência mental tal qual formulado por Stuart Mill (1843), o qual, na esteira da psicologia associacionista de seu pai James Mill (1773-1836), visava a descobrir os princípios pelos quais pensamentos ou ideias conscientes interagiam ou afetavam uns aos outros. Em suas investigações, Stuart Mill postulou, genericamente, que as combinações de ideias poderiam produzir resultantes capazes de ultrapassar suas partes mentais constituintes.

É de Stuart Mill, em A System of Logic (1843), a defesa de que a maioria das leis e efeitos da natureza segue o princípio da composição de causas. Mill (1843) atesta, por meio deste princípio, que o efeito conjunto de várias causas é idêntico à soma de seus efeitos separados (MILL, 1843, p. 371). Todavia, alega Mill, este princípio é, por vezes, violado. A combinação química de dois reagentes pode, por exemplo, resultar em um produto que exiba propriedades diferentes das propriedades apresentadas pelos reagentes separadamente ou em conjunto (MILL, 1843, p. 371). No que concerne aos fenômenos orgânicos, a violação às vezes parece ser ainda mais evidente, pois os fenômenos da vida, e mais estritamente a mente humana "não têm analogia com nenhum dos efeitos que seria produzido pela ação dos elementos constituintes considerados meros agentes físicos” (MILL, 1843, p. 371).

A partir desta breve, mas, no entanto, importante retrospectiva histórica, encaminhamos a noção de emergência a ser sustentada aqui, a qual se alicerça em um substrato metodológico, estrutural, teórico e conceitual naturalista. Mais especificamente, o emergentismo ao qual estamos mais propriamente alinhavados é o nomeado como emergentismo fraco, proposto por Stephan (1998, 1999). Um primeiro motivo para essa filiação decorre do fato de creditarmos a esta forma de emergência a possibilidade de fornecer a base para outras matizes de emergência que não queremos deixar de lado. Ademais, permite-nos pensar a emergência a partir do que a visão fraca considera como as três teses primárias de qualquer posição emergentista: (i) naturalismo, expresso pelo monismo físico; (ii) a alegação de que existem propriedades sistêmicas; e, por fim, (iii) a tese do determinismo sincrônico.

Ainda que essas três teses basilares não sejam suficientes para exaurir a posição emergentista no que diz respeito à relevância causal de níveis superiores, não é dispensável frisar o quão relevantes são para o panorama teórico emergentista. As duas 
primeiras teses gozam de amplo consenso entre os emergentistas naturalistas, e a terceira tese deve ser problematizada por quem ambiciona defender uma perspectiva emergentista fisicalista ou naturalista no viés não-reducionista. Exporemo-nas, em síntese, buscando captar os seus aspectos mais essenciais.

(i) A tese do monismo físico sustenta que todas as partes constituintes do universo são exclusivamente físicas. Portanto, toda a miríade de complexas relações apresentadas nos mais diversos níveis do universo é completamente constituída por estas partes físicas (MOGRABI, 2008, p. 113).

Para Mograbi (2008, p. 113), a tese do monismo físico poderia ser interpelada, justificadamente, por parte de um interlocutor que exija uma definição mais precisa de físico. Uma boa resposta seria: "tudo aquilo que é constituído por partículas em campo de força e/ou campos de força" (MOGRABI, 2008, p. 113). Adiante, Mograbi assevera que, se o interlocutor não se satisfizesse com a resposta, questionando, adicionalmente, de qual física atual o emergentismo trata, o proponente da tese do monismo físico poderia afirmar: mesmo não sendo completa, trata-se da física que descreve "tudo aquilo que é apresentado pelo somatório do modelo padrão da relatividade geral, suas revisões e tentativas de unificação" (MOGRABI, 2008 p. 113). Importante salientar que, para além de oferecer uma resposta plausível no interior das fronteiras da física, reconhecendo, assim, seus limites epistêmicos e epistemológicos, é preciso enfatizar que, apesar de a física estar em consonância com o monismo físico, o debate não se encerra no seu campo teórico porque esta tese reivindica ser pleiteada em termos filosóficos (MOGRABI, 2008, p. 114).

A tese do monismo físico contribui sobremaneira para o encaminhamento de uma posição teórica não só em relação ao problema das relações mente-corpo, mas também acerca do estatuto básico da consciência e de seu lugar na natureza. O monista físico é, em termos gerais, aquele que adota a visão de mundo segundo a qual o universo fornece uma explicação simples para a existência da consciência, embora esta visão de mundo se apresente imensamente rica em detalhes. Neste contexto, serve-nos de inspiração o biólogo austríaco Bertalanffy, que, em 1968, publica a Teoria Geral dos Sistemas, obra na qual defende a tese de que o universo se constitui de partículas e que estas partículas estão organizadas em sistemas.

(ii) A tese das propriedades sistêmicas reivindica que propriedades emergentes são propriedades que estão nos sistemas sem, no entanto, estarem presentes em suas partes: "Propriedades emergentes são propriedades sistêmicas. Uma propriedade é uma propriedade sistêmica", se e somente se "um sistema a possuir, mas nenhuma parte do sistema possui" (STEPHAN, 1999, p. 50). Esta definição abarca a explicação da existência de uma série de propriedades que, no mundo natural, são instanciadas apenas no nível dos sistemas, desde, por exemplo, as características sistêmicas da solvência da água até propriedades específicas de determinados grupos neuronais os quais apresentam características que não são exibidas em neurônios isoladamente. Logo, inflexiona-se que há propriedades que se aplicam ao 'todo', mas não as suas partes.

(iii) A tese da determinação sincrônica, tal qual apresentada por Stephan (1999, p. 50), institui que "as propriedades e disposições comportamentais de um sistema dependem nomologicamente de sua microestrutura", isto é, "das propriedades de suas partes e sua organização", de modo que não pode haver "diferença nas propriedades sistêmicas sem que haja alguma diferença nas propriedades das partes do sistema e/ou em sua organização".

Estampada esta definição, percebemos sua compatibilidade com as abordagens redutivistas contra as quais o emergentismo se posiciona. Não à toa, a posição do determinismo sincrônico enfrenta um problema fundamental relativo às propostas 
emergentistas pensadas a partir do materialismo não-redutivista. Com efeito, a tese do determinismo sincrônico, segundo Stephan (1998, p. 642), "é indiscutivelmente compatível com abordagens reducionistas contemporâneas".

Podemos então nos perguntar: por que então dispensar atenção à tese do determinismo sincrônico se a marca do emergentismo é sua incompatibilidade com o materialismo não-redutivista?

Uma resposta possível, segundo Mograbi (2008), é a de que a tese do determinismo sincrônico traz consigo dois méritos. $\mathrm{O}$ primeiro mérito a ser levado em conta é o seguinte: (i) ainda que pudéssemos postular um cenário no qual todas as propriedades sistêmicas fossem emergentes, o grande ganho conceitual de postularmos a tese do determinismo sincrônico reside na demonstração de que essas propriedades não são redutíveis às partes de um sistema mesmo que pudessem ser 'cabalmente' explicadas por estas partes que o compõe. Por sua vez, o segundo mérito tomado pela ótica emergentista diz respeito à capacidade explicativa da tese da determinação sincrônica sobre as condições mínimas para o surgimento de propriedades sistêmicas em um mundo puramente físico.

Qualquer versão mais forte de emergência terá que partir das três teses da emergência fraca somadas a teses adicionais, sobretudo, como nos apresenta Stephan (1998, 1999), a tese dos modos gerais de irredutibilidade, a saber: (i) o critério da irredutibilidade baseado na não-analisabilidade e (ii) o critério da irredutibilidade baseado na não-dedutibilidade.

O primeiro modo de irredutibilidade é baseado na noção de não-analisabilidade das propriedades sistêmicas: "Propriedades sistêmicas que não podem ser analisadas em termos do comportamento das partes do sistema são necessariamente irredutíveis" (STEPHAN, 1998, p. 643).

Vejamos o quão problemático pode ser este pressuposto: se considerarmos que um fenômeno emergente é marcado pelo critério da não-analisabilidade, estamos, em consequência, afirmando que tal fenômeno deve ser tomado como inexplicável sob o prisma da metodologia que inere às nossas melhores ciências. Se assim o for, é muito provável que estas propriedades emergentes sejam vistas com desconfiança, como algo misterioso, de onde pode resultar a compreensão de que os sistemas naturais têm pouco a contribuir nesta seara.

A adoção ou conivência com esta compreensão nos 'catapultaria' na direção do hiato ou lacuna explicativa (LEVINE, 1983; CHALMERS, 1996), concepção teórica da qual resulta as noções de easy e hard problem, e das quais resultam, por sua vez, a consideração de que a experiência consciente se compõe de um campo de fenômenos irredutíveis e, no mesmo sentido, passíveis de explicação.

A fim de apresentar um remédio para as possíveis aporias possivelmente suscitadas pelo hiato explicativo, recorremos ao texto de Almada (2018) por ocasião do seu estudo acerca do projeto neurofenomenológico de Varela (1996). Trata-se do projeto iniciado formalmente em The embodied mind (VARELA; THOMPSON; ROSCH, 1991), e cujo propósito é o de articular metodologicamente o problema da relação entre a experiência vivida com a neurociência e o 'problema difícil' da consciência. Para tanto, partiu da premissa de que o problema das relações mente-corpo é um problema que não prescinde da experiência direta, de primeira pessoa. Sobre isso, Almada (2018) se posiciona traduzindo Thompson (2004, p. 382):

É uma questão de como representamos cientificamente a mente se a concebermos como não-homuncular, como não restrita aos limites do crânio, ou ainda, se a concebermos como não-substancial. Por outro lado, podemos conceber a natureza da mente a partir de uma experiência direta, de primeira pessoa, e, para isso, 
importa apenas, pelo menos em princípio, que sejamos capazes de ter a experiência consciente qualitativa/fenomenal de 'como-é-estar' ou 'como-é-ser', ou ainda, a experiência direto-qualitativa e fenomenal da natureza da mente.

Por trás dessa compreensão, reside a crença de que o êxito da pesquisa empírica no que concerne às correlações entre cérebro, consciência, mente e comportamento não inviabiliza a natureza irredutível, fenomenal e qualitativa da mente consciente. Essa dupla dimensão da mente só é acessível por meio da consideração da mente a partir de alguma disciplina fenomenológica em relação à experiência vivida (THOMPSON, 2007; VARELA, 1996; VARELA; THOMPSON; ROSCH, 2003).

Se o primeiro critério se assenta em termos de analisabilidade, o segundo critério se estabelece em termos de dedutibilidade. A irredutibilidade segundo o critério da nãodedutibilidade é garantida mesmo diante do escrutínio ou analisabilidade das propriedades sistêmicas: "O comportamento específico dos componentes de um sistema dentro do sistema é irredutível se não resultar do comportamento dos componentes isoladamente ou em outras constelações (mais simples)" (STEPHAN, 1999, p. 52).

Perante a impossibilidade de redução de um sistema de maior complexidade às propriedades dos componentes deste sistema em isolamento ou em totalidade de menor complexidade, parecem-nos plausíveis as hipóteses de que (i) o mundo é estruturado em níveis, e de que (ii) níveis superiores apresentam novidades ontologicamente irredutíveis em relação as suas partes constituintes. Logo, estas hipóteses também nos parecem plenamente compatíveis com a tese do monismo físico, ou melhor, com a possibilidade de situar o lugar da consciência na natureza.

\section{EMERGENTISMO VERSUS REDUCIONISMO. DAS NOÇÕES DE COMPOSIÇÃO E DECOMPOSIÇÃO NAS TEORIAS EMERGENTISTAS (PROBLEMA TODO-PARTES) AO NATURALISMO BIOLÓGICO de SEARLE E À COMPREENSÃo de VARELA dA AUTOPOIESIS: VIDA E MENTE À LUZ DA EMERGÊNCIA}

O debate teórico emergentismo versus reducionismo não pode prescindir da lida com o que as melhores ciências atuais disponíveis têm a dizer acerca dos problemas teóricos relacionados com a estrutura do mundo natural, a exemplo da discussão naturalmente interdisciplinar acerca do 'espaço' ocupado pela mente no mundo natural. Nesse debate, algumas questões não só desafiam a posição reducionista, mas sinalizam, em simultâneo, a maior plausibilidade da posição emergentista. Eis uma dessas questões, formulada, aqui, de duas maneiras opostas: Os constituintes básicos da realidade compõem, aditivamente, todos os objetos complexos do mundo? Objetos complexos, por outro lado, são redutivamente decomponíveis de modo a abarcar compreensivamente seus constituintes básicos? Não precisamos ir longe para encontrar casos que desafiam este entendimento. A propriedade de solvência da água, por exemplo, não está presente nos seus constituintes isoladamente (moléculas de hidrogênio e oxigênio). Podemos dizer que a solvência emerge enquanto novidade ontológica de nível superior das interações entre estas moléculas?

Abre-se o debate nos domínios da ontologia quando questionamos se o todo é um arranjo ou uma soma de partes, e nos defrontamos com a percepção sugestiva de que o todo parece ser 'maior' que a soma das partes. Essa irredutibilidade exibida pela não-dedutibilidade é compatível com o pressuposto de que o sistema apresenta propriedades com características particulares de nível superior que não estão instanciadas em suas partes.

Ao lançar mão das noções de composição e decomposição plasmadas nas teorias 
emergentistas em resposta às perspectivas explanatórias reducionistas, consideramos relevante apresentar a distinção entre os conceitos de emergentismo sincrônico e diacrônico. Geralmente, essas duas modalidades de emergentismo estão intimamente relacionadas, aparecendo por vezes em uma única teoria da emergência.

$\mathrm{O}$ emergentismo sincrônico está interessado nas relações entre as propriedades sistêmicas e suas microestruturas. Já o emergentismo diacrônico se interessa pelo modo por meio do qual as propriedades emergentes são instanciadas na evolução, focando na noção de imprevisibilidade das propriedades sistêmicas (VIEIRA, 2009, p.7). Ambas as modalidades de emergentismo são importantes para a compreensão da defesa sobre a irredutibilidade dos estados mentais.

Salvaguardando o interesse de compreendermos melhor a propriedade de irredutibilidade das propriedades sistêmicas, ressalvamos que uma diferença elementar entre as duas modalidades está relacionada ao aspecto do tempo. O emergentismo sincrônico aponta para uma relação atemporal entre a propriedade de um sistema e sua microestrutura (STEPHAN, 1998, p. 640). Em contraste, o emergentismo diacrônico, ao adicionar uma dimensão temporal, passa a se ocupar principalmente da previsibilidade de novas propriedades, consideradas emergentes na medida em que não poderiam ser previstas antes de sua primeira instanciação, ou, em outros termos, uma vez que são imprevisíveis, em princípio, antes da sua primeira aparição (STEPHAN, 1998, p. 640).

$\mathrm{O}$ aspecto do tempo que inere ao emergentismo diacrônico pode enriquecer sobremaneira a discussão acerca da existência de fenômenos mentais irredutíveis a partir de uma perspectiva da biologia evolucionária. Ao mesmo tempo, o aspecto do tempo se articula de forma exitosa com a tese da determinação sincrônica. A modalidade da determinação sincrônica assegura o vínculo das propriedades e disposições do sistema às partes do portador, sem lançar mão de fatores não-naturais ou admitir propriedades 'flutuantes' (STEPHAN, 1998, p. 641). Dito de outro modo, a atribuição de poderes causais ou influência das propriedades sistêmicas em relação à sua microestrutura evita a conclusão de que propriedades emergentes sejam consideradas meras propriedades epifenomenais.

No que diz respeito à propriedade de irredutibilidade dos fenômenos mentais, e interpretados à luz do determinismo diacrônico, há boas razões para se pensar que a evolução das faculdades humanas não decorreu de uma linha de evolução única, e tampouco que decorreu de uma simples progressão na complexidade dos organismos. A biologia evolucionária aponta para uma co-evolução que envolveu e envolve uma complexa e indissociável relação de sistemas nervosos e corpos integrados, e, em interação com ambiente estruturado socialmente (DAMASIO, 2018, p. 87).

Ao propormos examinar a evolução dos fenômenos mentais à luz dos recursos do determinismo diacrônico, deparamo-nos com o conceito de novidade estampado por Stephan (1998, p. 645):

No decorrer das evoluções, exemplificações de 'novidades genuínas' ocorrem 'novamente e novamente'. Os blocos de construção já existentes desenvolvem novas constelações, novas estruturas são formadas constituindo novas propriedades e novos comportamentos.

A tese da novidade associada à tese da imprevisibilidade nos conduz a uma perspectiva que goza de certo consenso entre os emergentistas. Os emergentistas tendem a ser cordatos quanto ao fato de esperar que propriedades emergentes representem novidades adicionais à ontologia do mundo. Para Stephan (1998, p. 645), por um lado, adicionar a tese da novidade ontológica enquanto propriedade sistêmica 
não traz prejuízos à variante emergentista fisicalista. Por outro lado, a adição da tese da imprevisibilidade, em princípio, favorece a tese de que o sistema pode apresentar propriedades irredutíveis por serem imprevisíveis antes da sua primeira manifestação (STEPHAN, 1998, p. 645). Outra interpretação possível seria a de que, o fato de as propriedades sistêmicas exibirem características não instanciadas em suas partes, demonstraria assim, que a novidade ontológica poderia ser postulada como um modo peculiar de existir do fenômeno em relação aos seus mecanismos basais que o soergueu.

Lançamos mão de um trecho da obra de Damásio (2011, p. 380) a fim de elucidar a importância da interação dos elementos ao longo do tempo. Ainda que sua obra não trate especificamente de emergentismo, Damásio explicitou o papel da interação, a imprevisibilidade dos fenômenos mentais diante desta interação ao longo da história evolutiva, e, também apontou para sofisticação dos fenômenos mentais marcados pelas suas condições qualitativas e irredutíveis:

Nos humanos, quando essas mentes conscientes se organizaram em coletivos de
seres semelhantes, tornou-se possível a criação de culturas e dos artefatos
externos que as acompanham. As culturas, por sua vez, influenciaram o
funcionamento dos cérebros no decorrer das gerações e acabaram influenciando a
própria evolução do cérebro humano. O cérebro é um sistema de sistemas. Cada
sistema é composto de uma elaborada interconexão de regiões corticais pequenas,
mas macroscópicas e de núcleos subcorticais, que são feitos de circuitos locais
microscópicos, os quais por sua vez são feitos de neurônios, todos eles ligados
por sinapses. O que os neurônios fazem depende do agrupamento neuronal local
ao qual eles pertencem; o que os sistemas executam dependem de como os
agrupamentos locais influenciam outros agrupamentos pertencentes a uma
arquitetura interligada; finalmente, a contribuição de um agrupamento para o
funcionamento do sistema ao qual ele pertence, seja ela qual for, depende de seu
lugar nesse sistema (DAMASIO, 2011, p. 380).

O exposto nos parece ir ao encontro da tese defendida por Stephan (1998, p. 640) quando postulou que todos os possíveis candidatos a propriedades emergentes, e dentre eles, de acordo com o seu exemplo, a vida e a mente são instanciadas apenas por sistemas de partículas dotadas de uma microestrutura física complexa o suficiente para fazer emergir a extraordinária consciência humana. Stephan (1998, p. 640-641), deste modo, 'abraça' uma posição naturalista, subscrevendo uma posição que não abdica da ciência empirista sem, no entanto, assinar a pauta redutivista.

Atrelado à agenda naturalista da consciência humana, aludimos às obras de Searle $(1992,2004,2010)$, nas quais verificamos a presença de uma teoria designada como naturalismo biológico, e a qual pleiteia encaminhar de modo mais adequado a existência e o lugar da consciência na natureza. O estudo de Searle (1992) tomou como objetivo central a libertação das 'amarras' do materialismo reducionista e do dualismo. Para Searle (1992), a consciência não deve ser pensada em separado do seu aparato físico. Por isso, ainda que Searle não tenha se comprometido diretamente com a teoria emergentista, ao definirmos a consciência como uma propriedade emergente de um sistema biologicamente organizado, implica dizer que os princípios de sua teoria se mostram compatíveis com o emergentismo.

Para Searle (2010, p. 1-2), a consciência é uma característica biológica de alguns sistemas da mesma forma que a mitose e a meiose são características biológicas de uma célula. Por isso, objetou as posições dualistas de qualquer espécie. O compromisso com a tese do fechamento causal do (domínio) mundo físico antagonizou com o dualismo tradicional, por um lado, que celebrou a dicotomia entre o físico e o mental concebendo duas substâncias distintas, e, por outro lado, debelou com o dualismo de propriedades, 
para o qual os estados mentais são considerados propriedades que nunca poderão ser integralmente mapeadas.

Com efeito, quando dualismo de propriedades alega que o mental se sobrepõe ao físico, tem que asseverar que os domínios mentais configuram propriedades que vão além das propriedades físicas (SEARLE, 1992). Daí porque, para Searle (2004, p. 702), o dualismo de propriedades é ingênuo: ao considerar que a consciência 'vaza' pelo comportamento dos neurônios no cérebro, está comprometida com a absurda ideia que, uma vez a consciência esguichada para fora dos neurônios, teria, em seguida, uma vida própria.

No que concerne ao materialismo redutivo, a rejeição de Searle (1992) diz respeito, dentre tantos outros fatores, à tendência redutiva de suprimir os estados efetivamente conscientes, de primeira pessoa, subjetivos e qualitativos. Esse é o caso, por exemplo, do behaviorismo, para o qual os interesses se restringiam aos fenômenos de terceira pessoa publicamente observáveis. Também se encaixam neste quadro os paradigmas reducionistas para os quais a consciência almeja ser definida por suas causas subjacentes, predicando-a em terceira pessoa, e acreditando, por exemplo, que através das tecnologias de imageamento das atividades cerebrais seria possível reduzir a experiência consciente às atividades nervosas.

Por vias paralelas ${ }^{1}$, Searle $(1980,1992,2004,2010)$ tem professado ideias afins às do emergentismo. Desde sua crítica, em Minds, brains, and programs, de 1980, à tentativa de analogia entre a mente e o trabalho simbólico do computador, Searle tem sustentado que a projeção de programas não é capaz de replicar os poderes causais do cérebro humano, a exemplo do que ocorre na intencionalidade. Como defende em Minds, brains, and programs (1980), não há a possibilidade de replicar artificialmente a intencionalidade senão por meio da duplicação dos próprios poderes causais do cérebro humano em nível biológico. Uma questão que talvez tenha escapado a Searle é a seguinte: ainda que os 'poderes causais do cérebro humano' não possam resultar diretamente de algoritmos, é verdade, por outro lado, que algoritmos possam ser construídos de modo a produzirem esses mesmos poderes causais. Ou seja: as propriedades mentais conscientes podem emergir de processos explícitos descritos (porém não-previstos) no nível dos algoritmos. Se um tal sistema é colocado em funcionamento, teríamos que a emergência da consciência seria uma composição de ambiente-corpo-algoritmo.

À luz da contribuição de Searle, e, adicionalmente, do seminal artigo Autopoiesis and a biology of intentionality, de Varela (1992) podemos nutrir que a compreensão de mente como propriedade emergente de seres vivos não prescinde de uma compreensão prévia do que é a vida, e de que decorre dessa inter-relação a possibilidade que temos de "sustentar a viabilidade das perspectivas emergentistas para investigar a origem da vida mental". O conceito de autopoiesis de Varela (1992) e sua descrição naturalista da emergência da intencionalidade são essenciais, acreditamos, para uma mais profunda compreensão da intencionalidade como uma propriedade emergente de sistemas vivos inseridos em um ambiente.

Com efeito, se consideramos que sistemas propriamente autopoiéticos - a exemplo de organismos vivos dotados de sistema nervoso - ó se mantêm em um razoável nível de auto-organização por causa de suas partes, e que suas partes só se mantêm por causa do funcionamento do sistema, temos, na compreensão autopoiética de Varela uma clara defesa de que as propriedades sistêmicas influenciam, a partir de mecanismos top-down, suas partes constituintes.

Dos argumentos aduzidos acima, não resta dúvida acerca da nossa sintonia coma posição sustentada por Varela (1992) em Autopoiesis and a biology of intentionality, 
mormente no que diz respeito à ideia de mente como propriedade emergente de um corpo vivo em interação com o ambiente:

Uma dimensão complementar de biologia básica que é central para enfocar nossa discussão é a natureza da relação entre as unidades autopoiéticas autônomas e seu ambiente. É evidente que um sistema autopoiético depende de sua milha físicoquímica para sua conservação como uma entidade separada; caso contrário, ele se dissolveria de volta nele. Daí a intrigante paradoxalidade própria de uma identidade autônoma: o sistema vivo deve se distinguir de seu ambiente ao mesmo tempo em que mantém seu acoplamento; esse acoplamento não pode ser separado, uma vez que é contra esse mesmo ambiente do qual o organismo surge. Ora, nesse acoplamento dialógico entre a unidade vivente e o ambiente físicoquímico, a balança pesa levemente para o vivente, pois tem papel ativo nesse acoplamento recíproco. Ao denotar o que é como unidade, no mesmo movimento denota o que permanece exterior a ela, isto é, seu ambiente circundante.

\section{NATURAlismo biológico: EnCAMinhamento do PROBlema das RelaÇões MENTE-CORPO}

O naturalismo biológico, tomado como referência para encaminhar o problema das relações mente-corpo, não deve tratar a vida mental como uma coisa ou não coisa, substância material ou imaterial, mas sim como processo, uma propriedade emergente de nível superior. Explicações neste campo teórico podem abrir diálogo com uma metafísica de processos, isto é, uma práxis filosófica para a qual os processos tendem a ser tratados como categorias ontológicas em detrimento do tratamento tradicional, que as concebe como entidades. Em Rescher (1996, p. 38) encontramos uma definição condensada e bastante esclarecedora acerca do que possa ser considerado um processo: "Processo pode ser definido como um grupo coordenado de mudanças na aparência da realidade, uma família organizada de ocorrências sistematicamente ligada umas às outras, seja causal ou funcionalmente".

A partir desta visão das redes complexas mediante a qual os processos passam a ser tratados no âmbito de categorias ontológicas, a concepção da vida mental pode ser concebida pela integração e interação entre níveis. Esta visão nos remete à estrutura de níveis que visa a discutir os elementos centrais de uma concepção de mundo emergentista segundo a qual os conceitos de novidade ontológica, autonomia e relações causais vêm à tona.

Diante deste panorama, visitamos Juarrero (2000, p. 32) em nossa análise do complexo fenômeno da mente consciente, endossando a sua posição:

Sistemas adaptativos complexos; suas relações entre níveis, embora complicadas,
são reais, não apenas epistemológicas. O surgimento de níveis de organização
relativamente autônomos acarreta o aparecimento de níveis de qualidades
relativamente autônomas; alterações quantitativas produzem mudanças
qualitativas.

Nesse sentido, parece-nos claro que a defesa da associação entre teoria da mente corporificada e emergentismo incide na conciliação entre os conceitos de dependência e autonomia, visto que, de uma parte, a constituição da mente depende dos mecanismos fisiológicos através dos quais cérebros, corpos e ambientes estão integrados, e há, de outra parte, uma autonomia qualitativa da mente emergente em relação aos seus mecanismos de base, expressa pela experiência consciente (subjetividade e qualia).

Adiante, e a favor da tese que busca posicionar qual seria o lugar da consciência 
na natureza, apresentamos dois parágrafos em que Dutra (2015, p. 841-865) explicita a evolução dos níveis na evolução dos seres vivos. Eis a definição:

A noção central da perspectiva emergentista é que o universo começou há milhões de anos contendo apenas realidades e propriedades físicas que, com o decorrer do tempo, deram lugar a novas realidades emergentes, as realidades vivas ( e suas propriedades emergentes ou segundo pavimento ) que, por sua vez, deram lugar a um novo tipo de realidade, tal como os seres sencientes e conscientes ( terceiro pavimento) que, por sua vez, deram lugar ao último pavimento da realidade, o social, a saber: as instituições e todos objetos culturais. O principal argumento do emergentista é que cada nível superior pressupõe - não apenas lógica, mas também ontologicamente- os níveis inferiores, mas é irredutível a esses níveis inferiores. Assim, para que haja formas de vida, algumas moléculas e suas propriedades devem existir primeiro; entretanto, os seres vivos possuem propriedades que não podem ser encontradas fora deles, mesmo que os mesmos compostos químicos sejam colocados uns com outros in vitro. É assim que sabemos que a vida depende não apenas das propriedades físico-químicas da matéria, mas também das propriedades biológicas. Além de depender de propriedades físico-químicas, a vida depende de um tipo de organização (DUTRA, 2015, p 841-865).

Portanto, quando pensamos na primeira tese emergentista (monismo físico) apresentada neste paper, buscamos compreender o modo como a teoria emergentista aqui defendida elucida a organização da vida em um mundo natural estratificado. Grosso modo, o emergentismo postula que a realidade se encontra estruturada em níveis, a exemplo do físico, do químico, do biológico, da senciência, da consciência e, dentre outras possibilidades, da sociedade. O 'pavimento' químico depende do físico, mas exibe propriedades ou processos que não podem ser reduzidos ao físico. $\mathrm{O}$ 'pavimento' biológico, por sua vez, depende do físico e do químico, mas, igualmente, não se reduz a eles, e assim acontece até que cheguemos ao 'pavimento' da sociedade. Percebe-se, então, o espectro da tese do monismo físico. Todos os níveis superiores são dependentes dos mecanismos dos níveis inferiores, a começar pelo nível de realidade abarcado exclusivamente pela ciência física, ainda que, ao mesmo tempo, haja uma independência qualitativa destes em relação aos seus eventos e/ou fenômenos de base.

Ao lidarmos com emergentismo, é importante mencionarmos que os emergentistas demonstram expressiva consensualidade quanto ao fato de que propriedades emergentes representem novidades adicionais à ontologia do mundo. Nesse sentido, a vida mental representa uma novidade ontológica em relação aos componentes físicos arranjados segundo leis bioquímicas e mecanismos neurológicos autônomos de um sistema integrado e em permanente interação. Importante frisarmos que, nesta perspectiva, o físico e o mental participam de modo indiferenciado e indissociável. Assim, a novidade ontológica não é capaz de distinguir o físico e o mental a tal ponto de constituir duas classes substanciais distintas.

Em condições de reciprocidade, o que vemos, por um lado, é a redutibilidade causal dos estados mentais (conscientes) ao nível da tríade corpo-propriamente-dito, cérebro e ambiente. Podemos falar, por outro lado, da irredutibilidade ontológica dos estados mentais (conscientes) ao corpo-propriamente-dito, cérebro e o ambiente. Tal afirmação não pode nos levar a incorrer no equívoco de conceber a constituição de duas classes substanciais distintas em razão da novidade ontológica presente no estabelecimento da mente (consciente), ainda que falemos de uma independência qualitativa e de uma novidade ontológica desta relativa aos seus eventos e/ou fenômenos de base. 
Em outros termos: esse argumento não pode ser contaminado pela concepção de que a novidade ontológica derivada dos arranjos nos quais as partes se integram e interagem produz uma nova classe ontológica. O cerne deste entendimento repousa no argumento de que a novidade ontológica não pode ser concebida como mudança radical da ontologia que envolve o físico e mental, uma vez que processos emergentes constituem, na verdade, um novo padrão organizacional, material e estrutural de organismos dotados de sistema nervosos, e os quais apresentam instâncias qualitativamente distintas sem constituir classes substanciais extras. Por conseguinte, o emergentismo defende que as propriedades mentais (conscientes) se inserem plenamente no mundo natural, ainda que irredutíveis às partes, processos e comportamentos a partir do sistema do qual emerge.

\section{DETERMINAÇÃO DESCENDENTE: INFLUÊNCIA DAS PROPRIEDADES SISTÊMICAS SOBRE SUAS PARTES CONSTITUINTES}

Outro desafio que se põe ao emergentista diz respeito ao modo como um fenômeno ou processo de nível superior (propriedade sistêmica) pode causar ou determinar ou, ainda, estruturar uma propriedade de nível inferior. Não trataremos de modo mais detido este tema, mas também não nos furtaremos a discuti-lo por ser tratar de uma temática 'capital' aos emergentistas. A atenção será destinada essencialmente ao problema das interações entre a mente e o corpo.

$\mathrm{O}$ enfrentamento do problema das relações causais entre os níveis levanta questões que são de grande relevo para os emergentistas. Como as propriedades de nível superior influenciam as propriedades de nível inferior? No que diz respeito à consciência, como os processos ou fenômenos mentais (qualitativos) influenciam os componentes físico-químicos do cérebro/corpo?

Juntamente com Mograbi (2008) e Vieira (2009), compreendemos que o conceito de determinação descendente é mais adequado que o de causação descendente para encaminhar esta discussão. Logo, se mostra compatível com as ciências contemporâneas e com o princípio do fechamento do mundo causal. Vieira (2009, p. 43) procede a uma distinção relevante entre determinação causal e determinação descendente que justificará o alinhamento anunciado:

A diferença entre determinação causal e descendente é marcante: enquanto a determinação causal é um evento produtivo, o qual produz efeitos, a determinação descendente é um evento subtrativo, que, restringe as possibilidades de comportamento dos componentes de um sistema. As restrições todo-partes (topdown) impostas pelo princípio organizador $\mathrm{W}$ sobre os componentes são limitadoras no sentido de que restringem as possibilidades de comportamento dos componentes, e, dessa forma, eliminam possíveis efeitos, ao invés de produzir novos. Assim, tornam possíveis que um sistema como um todo exiba um conjunto aumentado de capacidades, devido à coordenação do comportamento de suas partes. Mas restrições são também criativas, num sentido funcional, uma vez que permitem que os componentes participem eficientemente como membros de um conjunto de processos, através da canalização (channeling) ou do direcionamento de seu comportamento para uma coleção particular de atividades (VIEIRA, 2009, p. 43).

A partir desta ideia, segundo Vieira (2009, p. 67), há uma "relação determinativa lógica entre o princípio organizacional de nível superior e processos particulares de nível inferior". A fim de dar lugar a relações estatísticas entre processos organizacionais 
e processos particulares, Vieira (2009, p. 67) oferece o tratamento da influência determinativa nos termos de uma relação de propensão:

Se algumas entidades de nível inferior $\mathrm{a}, \mathrm{b}, \mathrm{c} . . ., \mathrm{n}$ se encontram sob influência de um princípio organizador geral $\mathrm{W}$, aquelas entidades apresentarão uma tendência a se comportarem de certas maneiras específicas, e, deste modo, de instanciar um conjunto de processos específicos. A influência determinativa neste caso é do princípio geral organizador de nível superior sobre processos particulares de nível inferior e pode ser formulada nos seguintes termos: se a,b,c,...., n estão sob influência de $\mathrm{W}$, então elas apresentarão uma tendência, uma disposição de instanciar um processo $\mathrm{p}$ ou um conjunto de processos $\{\mathrm{P}\}$.

Esta visão está em anuência com Mograbi (2008), quando expressa que o termo 'determinação descendente' é mais adequado que o de 'causação descendente' por delimitar o modo como as propriedades sistêmicas exercem influência sobre $o$ comportamento dos componentes deste sistema. Destarte, o papel desempenhado pelas propriedades qualitativas da mente está mais para restrição, seleção, organização, estruturação, determinação, supressão ou repressão do comportamento dos processos em níveis inferiores do que para causação propriamente dita (MOGRABI, 2008, p. 271). Associamo-nos ao explicitado, lançando luz ao problema por meio de um brilhante exemplo oferecido por Damásio (2012, p. 120-121) por ocasião do tratamento que ofereceu à inextricável relação de interdependência entre os diversos níveis de regulação ao longo das dimensões:

Um determinado mecanismo pode depender de outro mais simples e ser influenciado por um terceiro de complexidade idêntica ou superior. A atividade no hipotálamo pode influenciar a atividade neocortical, diretamente ou por meio do sistema límbico, e o inverso também acontece. Consequentemente, como se poderia esperar, há uma documentada interação cérebro-corpo e podemos vislumbrar também interações mente-corpo talvez menos visíveis. Considere-se o seguinte exemplo: a tensão mental crônica, um estado relacionado com a atividade de numerosos sistemas cerebrais no nível do neocortex, do sistema límbico e do hipotálamo, parece levar à produção excessiva de uma substância química, o peptídeo relacionado com o gene da calcitonina, ou CGRP (do inglês, calcitonin gene related peptide), nas terminações nervosas subcutâneas. Como consequência, o CGRP reveste em excesso a superfície das células de Langerhans, cuja função é a captura dos agentes infecciosos e sua entrega aos linfócitos para que o sistema imunológico possa combater sua presença. Quando se encontram completamente cobertas pelo CGRP, as células de Langerhans ficam inutilizadas e deixam de cumprir sua função protetora. O resultado final é uma maior vulnerabilidade do corpo à infecção, agora que a entrada principal se encontra menos defendida. E há outros exemplos de interação mente-corpo. A tristeza e a ansiedade podem alterar de forma notória a regulação dos hormônios sexuais, provocando não só mudanças no impulso sexual, mas também variações no ciclo menstrual. A perda de alguém que se ama profundamente, mais uma vez um estado dependente de um processamento cerebral amplo, leva a uma depressão do sistema imunológico, a ponto de os indivíduos se tornarem mais propensos a infecções e, em consequência direta ou indireta, mais suscetíveis a desenvolver determinados tipos de câncer. Pode-se morrer de desgosto, na realidade, tal como na poesia.

\section{ConsideraÇões finais}


Nosso artigo buscou sustentar a viabilidade das perspectivas emergentistas para a construção de teorias dedicadas ao problema das relações mente-corpo a partir da consideração de que um encaminhamento adequado para a questão central de filosofia da mente depende de um quadro estrutural, metodológico, teórico e conceitual naturalista e interdisciplinar, porém não-redutivista.

Direta e indiretamente, temos tentado defender que uma posição emergentista para o problema das relações mente-corpo não prescinde do apoio em uma concepção corporificada da mente e em suas posições basilares, e de que a associação entre as teses emergentistas e corporificadas de mente nos permitem defender uma tese para o problema das relações mente-corpo capaz de superar tanto as limitações do dualismo quanto, por outro lado, dos reducionismos cerebralistas.

Essa associação implica a simultânea consideração de que a mente (consciente) é uma propriedade emergente de nível superior de um organismo, composto da associação entre cérebro, corpo-propriamente-dito e ambiente. Por suas repercussões, nossa tese abarca o estudo de diferentes níveis de processamentos fisiológicos, funcionais e estruturais, os quais envolvem necessariamente o corpo-propriamente-dito, o cérebro e o ambiente. A visão emergentista proposta neste artigo buscou referendar, para fins do problema mente-corpo, o trato das propriedades sistêmicas, tomando-as como categorias ontológicas. Acreditamos que a ontologia deve ser compreendida como modo de existência, e não no seu sentido clássico, que estuda o ser como ele é. Portanto, em síntese, postula que as propriedades sistêmicas são inteiramente constituídas pelas partes presentes em níveis inferiores, desde que, entretanto, as concebamos como irredutíveis.

A tese da emergência da consciência concebida pelo viés naturalista nãoredutivista se opõe ao dualismo clássico porque este separa a mente e o corpo em substâncias. Também enfrenta o reducionismo em seu equívoco de divisão que, por um lado, reduz a propriedade de um todo às propriedades das partes, e, por outro lado, enfrenta o equívoco da composição, para o qual as propriedades das partes são cabalmente tributadas ao todo. Logo, ao compreendermos que propriedades e/ou processos mentais conscientes emergem a partir das relações de integração e interação entre o corpo, o cérebro e o ambiente, faz-se notar sem prejuízos que há uma distinção, em algum nível, das partes, propriedades e/ou processos mais básicos dos sistemas a partir dos quais a consciência emerge.

\section{REFERÊNCIAS}

ALMADA, L. F. Neurofenomenologia e meditação: breves apontamentos para o diálogo entre práticas contemplativas e as ciências cognitivas enativistas no século XXI a partir da noção emergentista de determinação descendente. Revista Simbio-Logias, v. 10, n. 13, p. 119-140, 2018.

BERTALANFFY, V. General system theory: foundations, development, applications. New York: George Braziller, 1968.

CHALMERS, D. The conscious mind: in search of a fundamental theory. New York: Oxford University Press, 1996.

DAMÁSIO, A. E o cérebro criou o homem: construindo a mente consciente. São Paulo: Companhia das Letras, 2011.

DAMÁSIO, A. O erro de Descartes: cérebro, razão e emoção. São Paulo: Companhia das Letras, 2012.

DAMÁSIO, A. O mistério da consciência: do corpo e das emoções ao conhecimento de si. São Paulo: Companhia das Letras, 2015.

DAMÁSIO, A. A estranha ordem das coisas: as origens biológicas dos sentimentos e da cultura. São Paulo: Companhia das Letras, 2018. 
DUTRA, L. H. Emergência sem níveis. Scientia Studia, v. 13, n. 4, p. 841-865, 2015.

JUARRERO, A. Dynamics in action: intentional behavior as a complex system. Emergence, v. 2, n. 2, p. $24-57,2000$.

LEVINE, J. Materialism and qualia: the explanatory gap. Pacific Philosophical Quarterly, v. 64, n. 4, p. 354-361, 1983.

MILL, J. S. A system of logic, ratiocinative and inductive, being a connected view of the principles of evidence, and the methods of scientific investigation. London: Longmans, 1843.

MOGRABI, G. J. C. Emergência, mente e decisão: a relevância causal de diferentes níveis. 2008. 332 p. Tese (Doutorado em Filosofia) - Universidade Federal do Rio de Janeiro, Rio de Janeiro, RJ, 2008.

RESCHER, N. Process metaphysics: an introduction to process philosophy. New York: SUNY Press, 1996.

SEARLE, J. Minds, brains, and programs. Behavioral and Brain Sciences, v. 3, n. 3, p. 417-424, 1980.

SEARLE, J. The rediscovery of mind: representation and mind. Cambridge, MA: Bradford Book, 1992.

SEARLE, J. The irreducibility of consciousness. In HAIL, J. (Ed.) Philosophy of mind: a guide and anthology. Oxford: Oxford University Press, 2004. p. 700-708.

SEARLE, J. Making the social world: the structure of human civilization. Oxford: Oxford University Press, 2010.

VIEIRA, F. S. Determinação descendente: as relações todo-partes em sistemas naturais. 2009. 100 p. Dissertação (Mestrado em Filosofia e História das Ciências) - Universidade Federal da Bahia, Universidade Estadual de Feira de Santana, Bahia, 2009.

STEPHAN, A. Varieties of emergence in artificial and natural systems. Zeitschrift fur Naturforschung, v. 53, n. 7-8, p. 639-656, 1998.

STEPHAN, A. Emergenz: von der Unvorhersagbarkeit zur Selbstorganisation. Dresden/Munique: Dresden University Press, 1999a.

STEPHAN, A. Varieties of emergentism. Evolution and Cognition, v. 5, n. 1, p. 49-59, 1999b.

THOMPSON, E. Life and mind: from autopoiesis to neurophenomenology. Phenomenology and the Cognitive Sciences, v. 3, p. 381-398, 2004.

THOMPSON, E. Mind in life: biology, phenomenology, and the sciences of mind. Cambridge, MA: Harvard University Press, 2007.

VARELA, F. Autopoiesis and a biology of intentionality. In: McMULLIN B. (Ed.) Proceedings of the workshop "Autopoiesis and Perception”. Dublin: Dublin City University, 1992. p. 0414.

VARELA, F. Neurophenomenology: a methodological remedy for the hard problem. Journal of Consciousness Studies, v. 3, n. 4, p. 330-349, 1996.

VARELA, F.; THOMPSON, E.; ROSCH, E. The embodied mind: cognitive science and human experience. Cambridge, MA: MIT Press, 1991.

VARELA, F.; THOMPSON, E.; ROSCH, E. A mente incorporada: ciências cognitivas e experiência humana. Porto Alegre: Artmed, 2003.

\section{Notas}

1 A um dos pareceristas anônimos desse trabalho, queremos agradecer pela contribuição para a construção do argumento que se inicia no ponto dessa nota e que se estende até o encerramento dessa seção. Sua sugestão foi por nós seguida na íntegra. A este parecerista, agradecemos também por nos ajudar a descortinar frutificantes possibilidades de pesquisa futura. 